Grytcishin L. E., Fira L. S., Lykhatskyi P. H., Fira D. B. Development of the inflammatory process and endogenic intoxication in colorectal cancer after the application of cytostatics and hepatoprotectors. Journal of Education, Health and Sport. 2020;10(10): 381392. eISSN 2391-8306. DOI http://dx.doi.org/10.12775/JEHS.2020.10.10.037

https://apcz.umk.pl/czasopisma/index.php/JEHS/article/view/JEHS.2020.10.10.037

https://zenodo.org/record/4598029

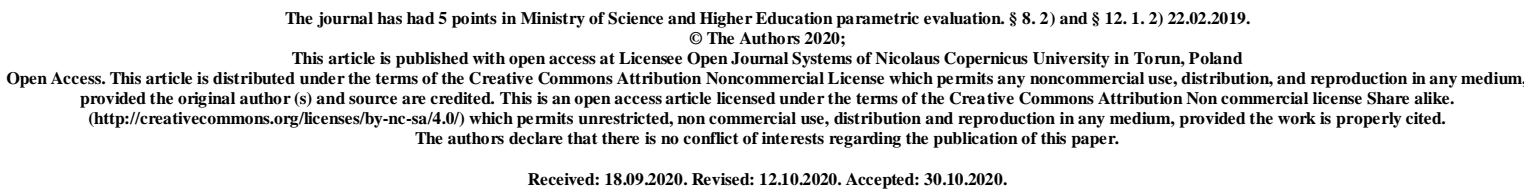

UDK 616-002+616-008.6]-02:616.348/.351-006.6-085:615.244/.277.3]-092.9

\title{
DEVELOPMENT OF THE INFLAMMATORY PROCESS AND ENDOGENIC INTOXICATION IN COLORECTAL CANCER AFTER THE APPLICATION OF CYTOSTATICS AND HEPATOPROTECTORS
}

\author{
L. E. Grytcishin, L. S. Fira, P. H. Lykhatskyi, D. B. Fira
}

\section{Horbachevsky Ternopil National Medical University of the Ministry of Health of Ukraine}

Abstract

Background: Considerable attention is currently drawn to inflammation as one of the main risk factors in the development of colon cancer. The aggravation of endogenous intoxication under conditions of the oncological process is observed concurrently with the development of inflammatory processes in the body. [19]. The objective need for cytostatic therapy occurs under the development of colorectal cancer to inhibit tumor growth. It has been substantiated that cytostatic therapy can cause almost all known forms of hepatic diseases, which leads to the necessitate use of adjunct medication to eliminate the adverse effects of the cytostatics.

Material and methods: The experimental studies were conducted on white rats kept on a standard diet in the vivarium conditions. All procedures were performed in compliance with the regulations of «The European Convention for the protection of vertebrate animals used for experimental and other scientific purposes». The carcinogen 1,2dimethylhydrazine.(DMH) was injected subcutaneously in the interscapular region at a dose of $7,2 \mathrm{mg} / \mathrm{kg}$ of body weight once a week for 30 weeks. The medication Xeloda was daily 
administered by an intragastric route at a dose of $134 \mathrm{mg} / \mathrm{kg}$ of animal's body weight for 21 days, starting immediately after 7-month modeling of the oncological process. The hepatoprotector Glutargin was administered to eliminate adverse effects of thecytostatic upon the liver at a dose of $130 \mathrm{mg} / \mathrm{kg}$ for 21 days after modeling the oncological process and effect of the cytostatic agent Xeloda. Levels of pro- and anti-inflammatory interleukins in blood serum were determined by immunoenzyme technique. The endogenous intoxication level was measured through the accumulation of middle molecules in the blood serum.

Results and Discussion: It was established that the concentration of markers of endogenous intoxication in the blood serum - middle molecules of both fractions (with the predominance of branched-chain and aromatic amino acids) increased within seven months of dimethylhydrazine administration, reaching the peak concentration over the last month of the conducted experiment (the increase was 2.9 and 2, 8 times, respectively). The augmented concentration of pro-inflammatory IL-6 (by 3,6 times), as well the decreased concentration of anti-inflammatory IL-4 (by 50\%) were determined within the same experimental period, indicating the development of inflammatory processes under conditions of colon cancer in rats. The cytostatic agent Xeloda, administered for 21 days, exacerbated the revealed disorders after the adenocarcinoma modeling. An even greater increase in the content of middle molecules, as well as the imbalance in the levels of cytokines, were observed after the administration of cytostatic. The level of pro-inflammatory cytokine was exaggerated by $28 \%$ compared to the experimental group of animals with dimethylhydrazine-induced carcinogenesis for 7 months. The hepatoprotector Glutargin, administered to eliminate adverse effects of the cytostatic, evidenced its efficacy under these conditions. The use of the hepatoprotector caused the decrease in the concentration of IL- 6 by 1,7 times compared to the animals with induced adenocarcinoma administered the medication Xeloda, which indicates the inhibition of inflammatory processes under the pathological process.

Conclusions: It has been evidenced that administration of the hepatoprotector Glutargin leads to the normalization of the studied parameters in rats with induced carcinogenesis that were administered the cytostatic agent Xeloda, indicating the prospects of further research of its effect on inflammatory processes and indicators of endogenous intoxication in the dynamics of colorectal cancer development.

Key words: experimental carcinogenesis; inflammatory processes endogenous intoxication; cytokines; cytostatic agents; hepatoprotectors 
Colorectal cancer (CRC) is considered to be a pluricausal disease. The causative factors in the development of colorectal cancer have been related to age, gender, diet, alcohol consumption, tobacco smoking, heredity, genetic disorders, inflammatory diseases of the large intestine, and others. Colorectal cancer is sporadic in the majority of cases, without identified specific risk factors, and only in rare cases can its connection with such factors be traced [1].

Considerable attention is currently drawn to inflammation as one of the key risk factors in the development of colon cancer. $[6,8,9]$. Current researches are focused on the assessment of changes in immune system activity at different stages of cancer development. Cancer development in various organs is frequently associated with chronic inflammation, indicating the strong link between inflammation and carcinogenesis. [11]. Cytokines are key signals in the intestinal immune system and are known to participate in the disruption of controlled inflammation (physiological inflammation of the gut) [3]. Cytokines work as a network in vivo, firmly interacting with each other, which enables participation of the cytokines in gradual regulation of immunomodulating, inflammatory, and proliferative body's responses. Changes in the cytokine-producing activity of immunocompetent cells, identified in the presence of malignant neoplasms, are, potentially, one of the major factors in the abnormal antitumor immune response. [13].

The aggravation of endogenous intoxication in the presence of the oncological process has been observed concurrently with the development of inflammatory processes in the body. [19]. It's noted that endotoxemia of various origins is accompanied by an increased content of middle molecules (MMM), but the level of middle molecules correlates with the severity of the disease. The increased concentration of MMM in plasma appears in various pathological states and, in particular, oncologic diseases. The molecules mentioned above are the resulting products of protein and protein complexes degradation, and act as endotoxins, aggravating the endogenous intoxication in the affected body [15].

The objective need for the use of cytostatic agents occurs under conditions of the development of colorectal cancer to provide the inhibition of tumor growth. However, the low selectivity of antitumor compounds often contributes to the development of severely impaired functions of organs and body systems, which significantly complicates and decreases the efficacy of treatment. [18]. It has been substantiated that cytostatic therapy can cause almost all known forms of hepatic diseases (necrosis, fibrosis, cholestasis, steatosis, vascular disorders, etc.) According to the literature, the development of oxidative stress, endogenous intoxication, impaired antioxidant defense mechanism and activation of 
inflammatory processes are among the factors, which significantly impair the hepatic function in the neoplastic processes background.

Consequently, the search for effective methods of reducing the toxic load on the liver, as the primary organ of detoxification in the use of multi-agent chemotherapy, is an urgent task of modern oncology practice.

The aim of the study was to investigate the effect of the cytostatic agent Xeloda as well as the hepatoprotector Glutargin on the inflammatory processes and endogenous intoxication under experimental carcinogenesis in rats.

Material and methods. The experimental studies were conducted on 72 white male 6 months-rats initially weighing $180-190 \mathrm{~g}$. The animals were kept on a standard diet in the vivarium conditions of Ternopil National Medical University. All procedures were performed in compliance with the regulations of «The European Convention for the protection of vertebrate animals used for experimental and other scientific purposes (Strasbourg, 18.III.1986.)» [4].

The experimental animals were divided into several groups: control group - 6 rats; an experimental group of 1,2-dimethylhydrazine-treated rats - 42 rats, 6 of which were monthly withdrawn from the experiments (within 7 months); an experimental group of dimethylhydrazine-treated rats administered cytostatic drugs - 12 rats ( 6 rats of the group administered Xeloda within 14 days, another 6 animals- within 21 days). Two more experimental groups comprised of the dimethylhydrazine-treated rats administered Xeloda as well as the hepatoprotector Glutargin (6 rats of the group administered medication within 14 days, another 6 animals- within 21 days).

The 1,2-dimethylhydrazine (DMH) (Sigma-Aldrich Chemie $\mathrm{GmbH}$, manufactured in Japan, batch number D 161802) was preliminarily diluted with isotonic sodium chloride before administration. The carcinogen was injected subcutaneously in the interscapular region at a dose of 7,2 mg/kg (calculated on active ingredient) once a week for 30 weeks, based on the weight of the animal [17]. The control benchmark for animals administered DMH were rats, which were weekly subcutaneously injected in the same region with $0.1 \mathrm{ml}$ saline solution calculated on $100 \mathrm{~g}$ of body weight.

The medication Xeloda (Capecitabine) was used as an agent of cytostatic treatment. Considering the route of medication administration in treating cancer patients, Xeloda was daily administered intragastric (i.g.) at a dose of $134 \mathrm{mg} / \mathrm{kg}$ of animal's body weight for 21 days, starting immediately after 7-month modeling of the oncological process. The dose of the cytostatic was selected using the package insert of medication, and taking into account species 
susceptibility of the animals (recalculation was carried out in accordance with Yu.R.Rybolovlev). The hepatoprotector Glutargin was administered to eliminate adverse effects of the cytostatic upon the liver (i.g. at a dose of $130 \mathrm{mg} / \mathrm{kg}$ ) for 21 days after modeling the oncological process and effect of Xeloda.

The afflicted rats were monthly withdrawn from the experiment after the beginning of the study through euthanasia carried out under thiopental sodium anesthesia. Blood serum samples were collected for analysis.

Levels of pro- and anti-inflammatory interleukins in blood serum were determined using commercial enzyme immunoassay kits (Cgmp Enzyme Immunoassay Kit supplied by GE Healthcare, Great Britain) [2]. The endogenous intoxication level was measured through the accumulation of middle molecules in blood serum (MMM) (their low- and highmolecular-weight fractions [15].

All obtained data were processed to the statistical analysis [16] using STATISTICA 6.0 software. The results had a parametric distribution, so, the difference between groups was measured using the nonparametric Wilcoxon rank-sum test (The Mann-Whitney U-test) and Student's t-test for paired samples. The difference in probability of values was $p \geq 0,95$ (significance level P). Differences were considered as significant at $\mathrm{p} \leq 0,05$.

The results. It is established that the considerable defect in the cellular component of the immune system develops under chemical-induced carcinogenesis and its combination with cytostatic agents, which can be caused by excessive and unbalanced synthesis of pro- and anti-inflammatory mediators - interleukins [19]. The production of different cytokines generally causes the development of immune response, inflammatory responses, and processes of hematopoiesis. The imbalance between the number of these biological cell mediators groups determines, actually, the duration, nature of the progression, and consequences of the pathological process in the body. [10].

We have analyzed the particular classes of cytokines, such as anti-inflammatory mediator IL-4 and pro-inflammatory cytokine IL-6, to identify the cytokine profile alteration in the body of experimental animals under conditions of experimentally modeled pathological neoplastic processes complicated by the administration of cytostatic agent Xeloda and after treatment with the hepatoprotecor Glutarguin.

The conducted studies indicated a progressive increase in the level of IL-6 in the experimental group of animals with dimethylhydrazine-induced carcinogenesis model, which was 3,6 times exaggerated at the $7^{\text {th }}$ month of the experiment compared to the control level. (table 1). Concurrently, the level of IL-4 decreased by $50 \%$ in this experimental group in the 
same study period. The obtained experimental data corresponds to the literature data concerning the pro-inflammatory cytokine profile alterations under cancer diseases. [13].

Table 1 - Levels of cytokines in the blood serum of rats with dimethylhydrazine administration and after Glutargin treatment in the cytostatic therapy background. $(\mathrm{M} \pm \mathrm{m}$; $\mathrm{n}=72)$

\begin{tabular}{|c|c|c|}
\hline $\begin{array}{c}\text { Experimental groups of animals / period of } \\
\text { dimethylhydrazine administration }\end{array}$ & IL-6, pkg/l & IL-4, pkg/l \\
\hline Control group & $1,81 \pm 0,06$ & $1,23 \pm 0,04$ \\
\hline 1 month of administration & $3,12 \pm 0,08^{*}$ & $1,17 \pm 0,02$ \\
\hline 2 months of administration & $3,37 \pm 0,05^{*}$ & $1,08 \pm 0,03^{*}$ \\
\hline 3 months of administration & $3,59 \pm 0,05^{*}$ & $0,96 \pm 0,03^{*}$ \\
\hline 4 months of administration & $4,10 \pm 0,07^{*}$ & $0,75 \pm 0,02^{*}$ \\
\hline 5 months of administration & $5,04 \pm 0,06^{*}$ & $0,69 \pm 0,03^{*}$ \\
\hline 6 months of administration & $5,85 \pm 0,07^{*}$ & $0,66 \pm 0,02^{*}$ \\
\hline 7 months of administration & $6,44 \pm 0,05^{*}$ & $0,62 \pm 0,02^{*}$ \\
\hline 7 months of administration +Xeloda +Glutargin(14 days) & $6,07 \pm 0,21$ & $0,60 \pm 0,03$ \\
\hline 7 months of administration + Xeloda (21 days) & $6,95 \pm 0,14^{* *}$ & $0,72 \pm 0,02^{\#, \&}$ \\
\hline 7 months of administration +Xeloda +Glutargin (21 days) & $4,11 \pm 0,27^{\#, \&}$ & $0,75 \pm 0,03^{\#, \&}$ \\
\hline
\end{tabular}

Notes: $*_{-}$significant differences between parameters of control group and dimethylhydrazine-treated animals;

** - significant differences between parameters of carcinogen-treated animals and dimethylhydrazine-treated animals administered the cytostatic agent Xeloda;

\# - significant differences between parameters of dimethylhydrazine-treated animals and dimethylhydrazine-treated animals concurrently administered the cytostatic agent Xeloda and the hepatoprotector Glutargin;

\& - probable differences between parameters of dimethylhydrazine-treated animals administered Xeloda and dimethylhydrazine-treated animals concurrently administered the cytostatic agent Xeloda and the hepatoprotector Glutargin

An analogous, but more manifested tendency of the changes in levels of pro- and antiinflammatory cytokines was observed under the combined effect of DMH and cytostatic agent Xeloda. No indicated possible alterations were observed after seven months of DMH administration, as well as 14 days of treatment with Xeloda in rats. The level of IL-6 remained nearly at the same level.

The index was 3,8 times increased in the experimental group of dimethylhydrazinetreated rats administered Xeloda for 21 days compared to the control. Furthermore, the index exceeded the level of the experimental animals with the dimethylhydrazine-induced carcinogenesis model by $28 \%$. The results indicate a side effect of the cytostatic drug leading to more manifested development of inflammatory processes in the affected body. 
As a result, there is a need for the administration of hepatoprotector Glutargin to protect the liver from being toxically affected by the metabolites, which are produced during the development of the oncological process, and the metabolic products of cytostatic agents that can lead to the induction of inflammation in the affected body.

Pro-inflammatory cytokine levels were decreased in the group of animals with induced experimental carcinogenesis administered the cytostatic agent Xeloda simultaneously with the Glutargin for 21 days. Moreover, the parameter was noted significantly $(\mathrm{p} \leq 0,05)$ reduced (by 1,7 times) in this group up to the end of experiment in contrast to the group of rats without treatment with hepatoprotector.

The comparison of studied parameter in the group of animals with induced experimental carcinogenesis and animals administered Xeloda concurrently with Glutargin for 21 days showed the decreased level of IL- 6 by 1,56 times.

As a result, the administration of Glutargin contributes to a more substantial decrease in the pro-inflammatory cytokine levels in the blood serum of the rats affected by carcinogenesis in the cytostatic therapy background.

It is established that the initiation of cytokine storm, which consists of both proinflammatory cytokines and anti-inflammatory mediators, is the basis of the development of inflammatory process. The balance between two cytokine groups acting in opposite directions, mainly, determines the course and outcome of a disease. It has been found that IL4 has a powerful anti-inflammatory effect and plays the key role in the stimulation of the inflammatory response as well as suppresses the inflammatory function of monocytes and macrophages [12].

We evaluated the level of IL-4 in the blood serum of rats with DMH-induced oncological process. The studied parameter progressively decreased within seven months, starting from the $2^{\text {nd }}$ month of the study the decrease was significant $(\mathrm{p} \leq 0,05)$, and the level of IL-4 was 2-times lower than control until the end of the experiment. The anti-inflammatory cytokine was found to be moderately decreased after the 21-day administration of cytostatic treatment, and was practically similar to the corresponding values of dimethylhydrazinetreated rats. The use of Glutargin led to the increased level of IL-4 in the blood serum of rats (by 1,16 times after 14-days administration of medication compared to the DMH-treated animals and by 1,21 times after 21-days of administration).

The level of IL-4 increased after administration of the Glutargin concurrently with the Xeloda after 14 days and 21 days by 1,2 and 1,27 times, respectively, compared to the animals administered, solely, the cytostatic agent in the oncological process background. 
Consequently, the obtained results substantiate the Glutargin's positive effect on the development of inflammatory processes in the body of rats under experimental chemicalinduced carcinogenesis after the administration of the cytostatic therapy, which is indicated by partially restored imbalance of pro- and anti-inflammatory cytokines.

It is widely known that the level of middle molecules (MMM) varies depending on the metabolic status of the body, and, to a certain extent, has been recognized as the prognostic criterion for metabolic disorders. It has been shown that the concentration of middle molecules increases in the blood under various pathological conditions, with the level variation of the parameter. The accumulation of middle molecules, in addition to being a marker of endotoxemia, exacerbates the further course of the pathological process acting as secondary toxins as well as affecting the functioning of organs and systems. The indicator of MMM level is considered to be the main biochemical marker indicating the level of the pathologic protein metabolism [15].

The research findings regarding the MMM254 concentration in the blood serum of rats with induced experimental carcinogenesis and animals after administration of the corrective medication are demonstrated in Fig.1.

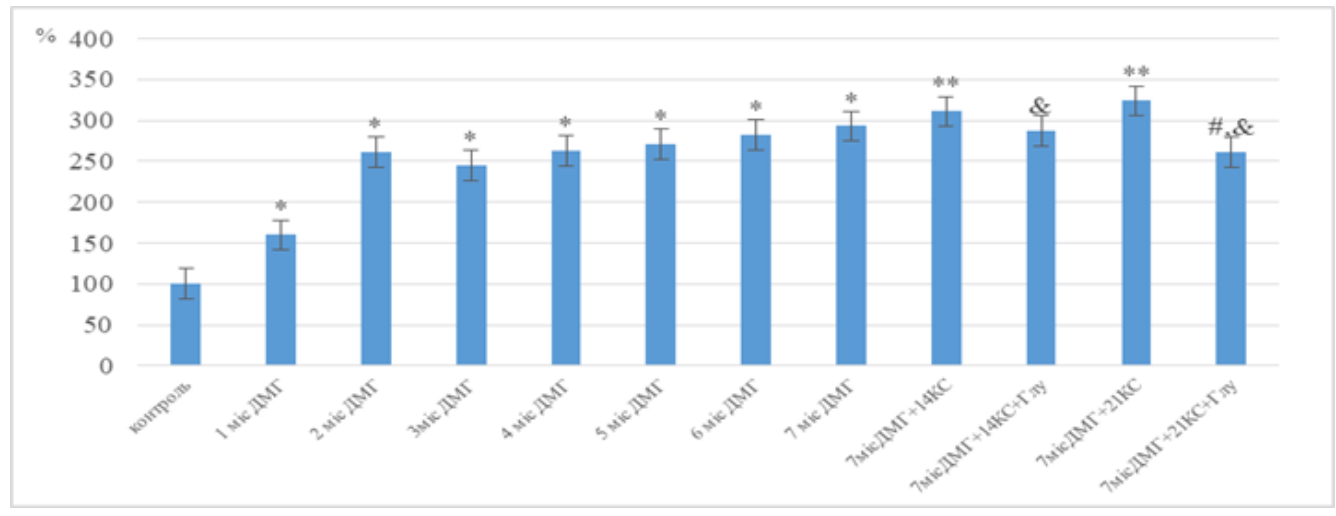

Fig. 1. The $\mathrm{MMM}_{254}$ concentration in the blood serum of rats under the administration of dimethylhydrazine and after Glutargin treatment in the cytostatic therapy background, \% Notes: * significant differences between parameters of control group and dimethylhydrazine-treated animals;

** - significant differences between parameters of carcinogen-treated animals and dimethylhydrazine-treated animals administered the cytostatic agent Xeloda;

\# - significant differences between parameters of dimethylhydrazine-treated animals and dimethylhydrazine-treated animals concurrently administered the cytostatic agent Xeloda and the hepatoprotector Glutargin;

\& - probable differences between parameters of dimethylhydrazine-treated animals administered Xeloda and dimethylhydrazine-treated animals concurrently administered the cytostatic agent Xeloda and the hepatoprotector Glutargin 
The $\mathrm{MMM}_{254}$ concentration progressively increased within the experimental period and reached the level of $293 \%$ at the $7^{\text {th }}$ month of the studies. The administration of the cytostatic agent Xeloda led to an even greater increase in the studied parameter (by $18 \%$ compared to the corresponding level of the animals treated with dimethylhydrazine over the last month). The $\mathrm{MMM}_{254}$ level increased by $13 \%$ after the administration of Xeloda within 21 days, compared with the previous period of its use, reaching the level of 324\% comparatively to the control group. Therefore, the cytostatic agent Xeloda does not contribute to the decrease in the concentrations of middle molecules (MMM) contained branched-chain amino acids in the blood serum of rats. The administration of the medication leads to the augmentation of the parameter.

The use of the hepatoprotector indicated the positive effect on the studied parameter: the significant decrease $(\mathrm{p} \leq 0,05)$ in the $\mathrm{MMM}_{254}$ level was evidenced within 14 and 21 days of its administration, compared to the animals administered cytostatic therapy after the development of experimental carcinogenesis.

The research findings concerning the $\mathrm{MMM}_{280}$ concentrations (the predominance of the aromatic amino acids) substantiated their increase within seven months of DMHadministration with the peak concentration in the end of the conducted experiment $(284 \%$ compared to the control level). The concentration of $\mathrm{MMM}_{280}$ significantly increased in the first two months of DMH-administration and moderately decreased in the next two months compared to the previous experimental period, with a following progressive increase (Fig.2).

The concentration values of MMM280 in the experimental group of rats induced carcinogenesis for seven months as well as the group of animals administered Xeloda in the oncological process background were practically at the same level, exaggerating the control level by 2,8 and 2,9 times respectively. The 21-day administration of Glutargin contributed to the significant increase in the studied value compared to the rats with carcinogenesis ( 7 month of the experiment).

The research findings regarding the $\mathrm{MMM}_{280}$ concerntrations in the blood serum of rats with carcinogenesis administered the cytostatic agent Xeloda concurrently with the hepatoprotector Glutargin evidenced the positive effect of the hepatoprotecor on the parameter. The concentrations of middle molecules with the predominance of the aromatic amino acids reduced after 14 days of Glutargin administration comparatively to the animals administered, solely, the cytostatics by $26 \%$, after 21 days - by $65 \%$. 


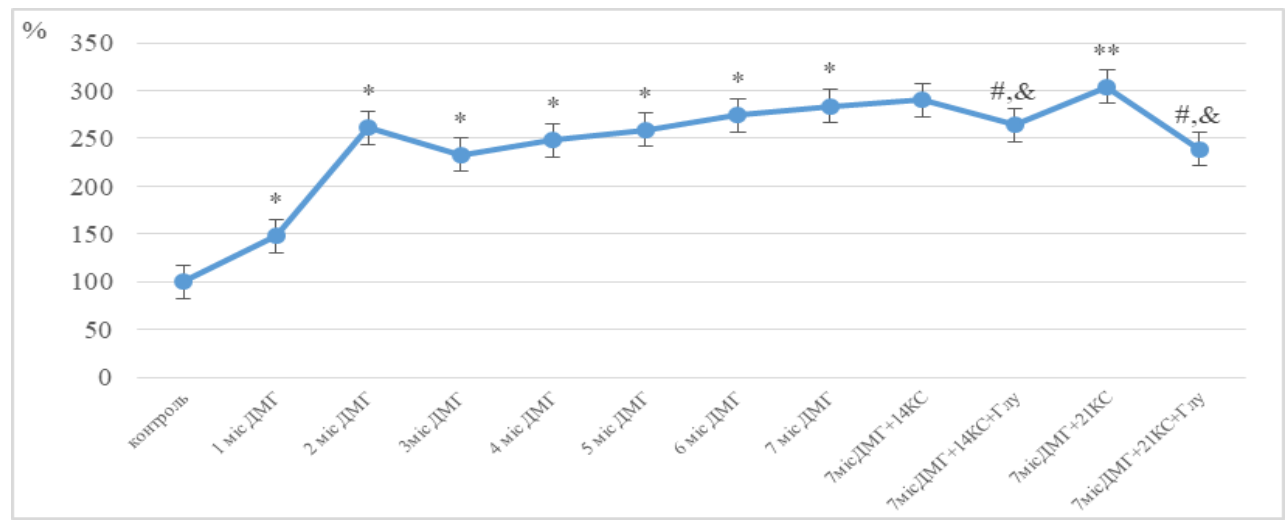

Fig.2.The $\mathrm{MMM}_{280}$ concentration in the blood serum of rats under administration of dimethylhydrazine and after Glutargin treatment in the cytostatic therapy background,\%

Notes: * significant differences between parameters of control group and dimethylhydrazine-treated animals;

** - significant differences between parameters of dimethylhydrazine-treated animals and dimethylhydrazine-treated animals administered the cytostatic agent Xeloda;

\# - significant differences between parameters of dimethylhydrazine-treated animals and dimethylhydrazine-treated animals concurrently administered the cytostatic agent Xeloda and the hepatoprotector Glutargin;

\& - probable differences between parameters of dimethylhydrazine-treated animals administered Xeloda and dimethylhydrazine-treated animals concurrently administered the cytostatic agent Xeloda and the hepatoprotector Glutargin

Consequently, the administration of Glutargin led to the normalization of MMM concentrations towards their decrease in the blood serum of rats with the DMH-induced carcinogenesis and treated with the cytostatic agent Xeloda.

Conclusions and Perspectives. The imbalance between pro-inflammatory and antiinflammatory cytokines has been observed under conditions of induced colorectal cancer. The level of pro-inflammatory cytokine IL-6 significantly increased as well as the level of antiinflammatory cytokine IL-4 significantly decreased within the seven months of the development of DMH-induced carcinogenesis. It, incontestably, is a consequence of the exacerbation of endogenous intoxication, evidenced by increased levels of $\mathrm{MMM}_{254}$ and $\mathrm{MMM}_{280}$ (by 2,9 and 2,8 times, respectively) at the end of the experiment. The cytostatic agent Xeloda, administered after colon cancer model within 21 days, conduced to an even greater augmentation of MMM levels of both fractions, which led to the marked imbalance in the levels of the interleukins. The decrease in the MMM concentration, as well as the normalization of balance between pro-inflammatory and anti-inflammatory cytokines were observed in the animals administered the cytostatic agent Xeloda concurrently with the hepatoprotector Glutargin in the oncological process background. 
The obtained results substantiate the pertinence of further research of these parameters under induced experimental carcinogenesis and administration of the cytostatic therapy as well as the investigation of the effect of hepatoprotector on inflammatory processes and endogenous intoxication in the presence of colorectal cancer, which will contribute to the ease of disease course, indicating the prospects of the medication in the standard treatment guidelines for cancer patients.

\section{References}

1. Dilip A., Ranawat MS, Khinchi-Mahaveer P, Gupta MK, Sharma N., Gunjan A. Diagnosis and treatment of colorectal cancer: a review. Journal of Drug Delivery \& Therapeutics; 2012, 2(3): 60-66 60.

2. Gaber W, Azkalany GS, Gheita TA, et al. Clinical significance of serum interleukin-6 and $-174 \mathrm{G} / \mathrm{C}$ promoter polymorphism in Rheumatoid arthritis patients. Egypt Rheumatol. 2013 Apr;35(2):107-113.doi:10.1016/j.ejr.12.11.002.

3. Godos J, Biondi A, Galvano F, Basile F, Sciacca S, Giovannucci EL, Grosso G Markers of systemic inflammation and colorectal adenoma risk: Meta-analysis of observational studies. World J Gastroenterol; 2017, 23(10):1909-1919.

4. Gross D, Tolba R. Ethics in Animal-Based Research. Eur. Surg. Res. 2015; $55(1-2): 43-57$.

5. Klimov I. N. Gepatotoksichnost' lekarstvennykh sredstv intensivnoy terapii onkogematologicheskikh zabolevaniy, intensivnoy terapii onkogematologicheskikh zabolevaniy, transplantatsii kostnogo mozga i gemopoeticheskikh stvolovykh kletok. Lechebnoye delo;2014,5 (39):68-73 [in Russian].

6. Krzystek-Korpacka M., Diakowska D., Kapturkiewicz B., Profiles of circulating inflammatory cytokines in colorectal cancer (CRC), high cancer risk conditions, and health are distinct. Possible implications for CRC screening and Cancer Lett; 2013, 337(1):107-14.

7. Kurmukov I. A. Lekarstvennoye porazheniye pecheni pri lechenii onkogematologicheskikh zabolevaniy. Klin. Onkogematologiya; 2010,3 (1):60-66 [in Russian].

8. Lakatos L., Mester G., Erdelyi Z. Risk factors for ulcerative colitis-associated colorectal cancer in a Hungarian cohort of patients with ulcerative colitis: results of a population-based study. Inflamm Bowel Dis; 2006,12(3):205-11.

9. Lee W. S., Baek J. H., You D. H. Prognostic value of circulating cytokines for stage III colon cancer . J. Surg Res; 2013, 182(1): 49-54. 
10. Lykhats'kyy P.H., Fira L.S. Dynamika markeriv zapalennya pid vplyvom mildronatu za eksperymental'noho urazhennya shchuriv tyutyunovym dymom ta natriyu nitrytom. Sciences of Europe. 2017;1(20):10-15 [in Ukrainian].

11. Maeda S., Omata M. Inflammation and cancer: Role of nuclear factor-kappaB activation. Cancer Sci;2008, 99(5): 836 - 842.

12. Manzhaliy E.H, Virchenko O.V, Falalyeyeva T.M., Berehova T.V., Savchuk O.M., Kondratyuk V.YE. Otsinka rivnya tsytokiniv pry eksperymental'niy pechinkoviy entsefalopatiyi u shchuriv. Klin.khirurhiya. 2016;10:63-66 [in Ukrainian].

13. Mikhaylova Ye.S., Velikaya N.V., Morozov D.V. Izmeneniya produktsii tsitokinov kletkami perifericheskoy krovi u bol'nykh kolorektal'nym rakom;."Novosti "Vektor-Best"; 2011,3:2 - 6 [in Russian].

14. Mikulyak N. I. Farmakologicheskaya korrektsiya oksidantnogo i metabolicheskogo statusa pri tsitostaticheskoy bolezni, vyzvannoy vvedeniyem khimiopreparatov. Izvestiya vysshikh uchebnykh zavedeniy. Povolzhskiy region. Meditsinskiye nauki; 2010,4: 36-43 [in Russian].

15. Nikol'skaya V.A., Danil'chenko YU.D., Memetova Z.N. Biokhimicheskiy aspekt rassmotreniya roli molekul sredney massy v organizme v organizme. Uchenyye zapiski Tavricheskogo natsional'nogo universiteta im. V. I. Vernadskogo Ser.: Biologiya, khimiya; 2013,1(65):139 -145 [in Russian].

16. Okeh U. Statistical problems in medical research. East. Afr. J. Public. Health; 2009, 6(1):1-7.

17. Onose J, Imai T, Hasumura M. Rapid induction of colorectal tumours in rats initiated with 1,2-dimethylhydrasine followed by dextran sodium sulfare treatment. Cancer Letters. 2003;198(2):145-152.

18. Remesha A. Toxicities of anticancer drugs and its management. International Journal of Basic \& Clinical Pharmacology; 2012,1(1): 2-12.

19. Soroka YU.V., Demkiv I.YA., Lisnychuk N.YE. Markery endohennoyi intoksykatsiyi ta stan imunnoyi systemy v orhanizmi bilykh shchuriv za umov khronichnoyi neoplastychnoyi intoksykatsiyi. tavrycheskyy medyko-byolohycheskyy vestnyk; 2012, 15(3), 1(59):308-310 [in Ukrainian]. 